\title{
Democracia constitucional contemporânea e separação de poderes: uma análise com base no presidencialismo de coalizão
}

\author{
Contemporary Constitutional Democracy and \\ separation of power: an analisys based on coalition \\ presidentialism
}

\author{
Fabrício Ricardo de Limas Tomio* \\ William Soares Pugliese ${ }^{* *}$
}

\section{Resumo}

O presente artigo pretende analisar se podem os representantes do Poder Executivo garantir a produção legislativa, cuja responsabilidade original é do Poder Legislativo. Para tanto, toma-se como exemplo prático e ponto de partida para o estudo as promessas do governo brasileiro à FIFA. Na tentativa de apresentar uma resposta compatível com a democracia constitucional contemporânea, em um primeiro momento, apresenta-se a teoria de uma outra separação de funções, concebida por Karl Loewenstein. Em seguida, estudase o presidencialismo de coalizão, com enfoque para as pesquisas empíricas que demonstram que as taxas de sucesso e de dominância do Poder Executivo na produção legislativa no Brasil são próximas dos níveis encontrados no parlamentarismo. Ao final, conclui-se que a função de determinação política, no Brasil, é exercida pela coalizão entre Executivo e Legislativo, tendo o Presidente como principal detentor do poder de agenda. Assim, é de fato possível que o Executivo faça promessas que envolvam a produção de legislação.

Palavras-chave: Separação de poderes. Função de determinação política. Presidencialismo de coalizão.

Doutor em Ciência Política - UNICAMP. Professor Associado de Teoria do Estado e Ciência Política do Depto. de Direito Público/UFPR e dos Programas de Pós-Graduação em Direito (PPGD/UFPR) e Ciência Política (PPGCP/UFPR). Curitiba - PR - Brasil. Email: fab_tom@ hotmail.com

* Doutorando em Direitos Humanos e Democracia pelo Programa de Pós-Graduação em Direito da Universidade Federal do Paraná. Mestre em Direito das Relações Sociais pelo PPGD/UFPR. Professor da graduação e pós-graduação da Universidade Positivo. Advogado. Curitiba - PR Brasil. Email:wpugliese@gmail.com 


\section{Abstract}

The present article aims to analyse if the representatives of the Executive Branch can ensure success on the legislative process, which is the unique responsibility of the Legislature? For this purpose, the promises of the Brazilian Government to FIFA are taken as a practical example and as a starting point for the article. In an attempt to provide an answer compatible with the contemporary constitutional democracy, at first the theory of another separation of functions, designed by Karl Loewenstein, is presented. On a second stage, we study the coalition presidentialism, focusing on empirical studies that demonstrate that the rate of success and dominance of the Executive Branch in legislative production in Brazil are close to the levels found in parliamentarism. The article concludes that the role of politicy determination, in Brazil, is exercised by the coalition between the Executive and the Legislature, having the President as the main agenda setter. Thus, it is indeed possible for the Executive Branch to promise the production of legislation.

Keywords: Separation of powers. Policy determination function. Coalition presidentialism.

\section{Introdução}

É do conhecimento do homem médio que o Estado brasileiro está organizado em três poderes: Executivo, Legislativo e Judiciário. As explicações clássicas costumam apresentá-los como entidades claramente distintas e com funções absolutamente diferentes, de modo que ao Legislativo caberia a elaboração e aprovação de leis, enquanto ao Executivo competiria a administração do Estado e a efetivação da legislação.

Ocorre, porém, que uma reflexão minimamente mais aprofundada a respeito da relação entre Executivo e Legislativo demonstra que esses poderes atuam, em alguns momentos, em conjunto para a determinação de políticas e para a elaboração de atos normativos. Tanto isso ocorre que o Presidente da República costuma ser identificado como o principal definidor de políticas, sejam elas sociais, econômicas, jurídicas, dentre 
outras, enquanto o Legislativo exerce o papel de discussão e aprovação democrática das propostas.

Uma análise com ainda maior cautela revela, no fundo, que a separação dos poderes contemporânea é bastante diferente e que o Poder Executivo exerce papel essencial para a elaboração da legislação. Uma análise fática demonstra, inclusive, que o Executivo se sente competente para assegurar ao povo e a outras entidades que tomará determinadas medidas, sem a necessidade de prévia consulta ao Congresso. O que garante essa segurança? Faria o Executivo parte do Poder Legislativo?

A tentativa de se responder a essa pergunta será realizada em três etapas. A primeira procura localizar a discussão a partir de um caso recente, cuja escolha se justifica pelo interesse popular despertado: os instrumentos normativos e políticos adotados pelo governo brasileiro para a realização da Copa do Mundo FIFA de 2014. Em especial, esse primeiro item examina como o Poder Executivo realizou uma série de "promessas" à FIFA e tratou de inseri-las no ordenamento jurídico após a escolha do Brasil como sede do evento.

A segunda etapa inaugura a análise teórica e trata da revisão da teoria da separação dos poderes, uma vez que os limites rígidos estabelecidos por Locke e Montesquieu não parecem ter espaço na configuração contemporânea do Estado brasileiro. Para tanto, partese da concepção de Karl Loewenstein (1965) acerca de uma nova tripartição de funções estatais.

O terceiro momento examinará a figura do presidencialismo de coalizão e a relação do Presidente da República com os partidos políticos da base aliada. Essa análise terá como base o trabalho de Fernando Limongi (2006) e fará alusões às teorias de Arend Lijphart (2012) e George Tsebelis (1998; 2002), na tentativa de atualizar a visão de Loewenstein e verificá-la de forma mais próxima do sistema brasileiro. Ao final, procura-se responder se o Presidente pode prometer ou garantir a edição de uma lei na configuração atual do Estado brasileiro. 


\section{Breve análise de caso: as garantias do governo brasileiro à FIFA para a realização da Copa do Mundo}

Em outubro de 2008, o Brasil foi anunciado pela FIFA (Fédération Internationale de Football Association), uma associação privada com sede em Zurique, Suíça, como o país-sede da Copa do Mundo de Futebol. O fato foi comemorado por alguns e criticado por outros, mas a partir daquele momento era certo que deveria ser dado início aos trabalhos para sediar o megaevento. Enganam-se, porém, aqueles que cogitam que a FIFA fez imposições ao Estado brasileiro após seu anúncio como país-sede. Pelo contrário, as exigências são feitas a priori, como condições para a participação dos países como candidatos a sediar a Copa do Mundo (BARBOSA et al., 2011).

Além de um documento produzido pela Confederação Brasileira de Futebol, que supostamente continha mais de 900 páginas que especificavam questões técnicas, o Estado brasileiro apresentou uma garantia de apoio governamental ao evento ${ }^{1}$. Esse documento, chamado de Carta de Intenções e redigido tanto em português quanto em inglês, era assinado pelo então Presidente da República, Luiz Inácio Lula da Silva². De início, o Presidente afirmava a "disposição" brasileira, comprovada pela assinatura de todas as garantias governamentais solicitadas pela FIFA.

Os requisitos para um país se candidatar como sede da Copa do Mundo não são claros. Sabese, porém, que a FIFA já eliminou propostas pela falta de apoio governamental, como no caso da Indonésia, que pretendia sediar a Copa do Mundo de 2018 ou 2022 (INDONESIA'S, 2013).

2 O principal ponto do documento é o seguinte:

"Asseguro à FIFA que o Brasil reúne todas as condições para receber os times, os torcedores e os organizadores do evento e proporcionar ao mundo um espetáculo memorável, dentro dos mais elevados padrões de excelência. Nos próximos anos, o País irá fazer o que for necessário para sediar esse grande espetáculo da bola, construindo novos estádios ou melhorando os já existentes. Temos uma infra-estrutura de transportes e hotéis e iremos aperfeiçoá-la ainda mais. Para isso, formamos uma única torcida, reunindo o melhor dos esforços dos governos federal, estadual e municipal, com apoio do Legislativo e do Judiciário, bem como da iniciativa privada e de toda a sociedade brasileira. Uma demonstração dessa disposição é o fato de termos assinado todas as garantias governamentais, solicitadas pela FIFA." (BRASIL, 2007, p. 2). 
O restante do documento contém mensagens de ministros assumindo o compromisso de realizar as alterações necessárias para adequar, material e formalmente, o Estado aos padrões da FIFA. Passase, assim, a uma breve análise dessas garantias. A primeira delas tem cunho formal e foi assinada pelo Presidente da República e pelo Ministro do Esporte, Orlando Silva de Jesus Jr. Nessa primeira mensagem, os representantes do Poder Executivo afirmam que

[...] todas as garantias emitidas pelos órgãos do Governo brasileiro à FIFA com relação à proposta submetida pela Confederação Brasileira de Futebol (CBF) para sediar as competições são válidas, bem como foram assinadas incondicionalmente pelas autoridades governamentais que possuem a competência para firmá-las. (BRASIL, 2007, p. 5).

Além disso, o Governo Federal se comprometeu a adotar todas as medidas necessárias e, se necessário e de acordo com a Constituição, "aprovar ou solicitar ao Congresso Nacional, às autoridades estaduais ou municipais que aprovem todas as leis, decretos, portarias ou regulamentos nacionais, estaduais ou municipais que possam ser necessários". Em outras palavras, o que os representantes afirmaram à FIFA é que tinham competência para garantir tudo o que foi prometido, mesmo que dependesse de alteração legislativa estadual ou municipal.

Com relação às garantias materiais, a primeira foi assinada pelo Ministro das Relações Exteriores, Celso Amorim. Prometeu-se que seriam emitidos vistos de entrada incondicionalmente para todos os membros da delegação da FIFA, seus oficiais, para as seleções, árbitros e demais afiliados. Houve, ainda, uma garantia semelhante para todos os estrangeiros portadores de ingressos para um dos jogos da Copa do Mundo.

A tudo isso o Ministro Celso Amorim acrescentou a garantia de que aprovaria (ou pediria ao Congresso, estados ou autoridades locais) "toda lei, regulamento, decreto e quaisquer outros regulamentos". Também foi afirmado que a Carta de Intenções

[...] é e deve permanecer vinculativa, válida e executável em relação ao Brasil e seu governo, assim como a todos 
os estados e autoridades locais, a partir da data desta garantia até 31 de dezembro de 2014, independentemente de quaisquer mudanças no governo do Brasil ou em seus representantes, ou quaisquer mudanças nas leis e regulamentos do Brasil. (BRASIL, 2007, p. 7).

As promessas acima descritas foram efetivamente cumpridas pelo Estado brasileiro por meio da Lei Geral da Copa do Mundo (12.663/2012), nos arts. 19 e seguintes.

A Carta de Intenções prossegue com a garantia de emissão de vistos de trabalho para todos os estrangeiros indicados pela FIFA e de que a legislação que trata das horas de trabalho não será um empecilho para a atividade das pessoas vinculadas e indicadas pela FIFA. Garantiuse também a total isenção de impostos e demais restrições para a importação e exportação dos bens necessários para a organização da Copa do Mundo de 2014, e a implementação de todas as medidas de segurança necessárias e suficientes para o evento, jogadores, funcionários e espectadores. O governo ainda se comprometeu a autorizar a entrada e saída, câmbio e conversão de dólares, euros e francos suíços para todas as negociações da FIFA, entidades e pessoas a ela vinculadas.

Todas essas garantias foram cumpridas e inseridas no ordenamento jurídico brasileiro, em parte pela Lei Geral da Copa do Mundo, em parte por outras leis e regulamentos editados com essa finalidade.

Os Ministérios da Justiça, Desenvolvimento, Cultura e Ciência firmaram em conjunto uma das mais controvertidas garantias à FIFA. Nela, asseguraram a proteção e a exploração dos direitos comerciais da Copa do Mundo apenas à entidade organizadora e seus patrocinadores. Essas medidas foram implementadas pela Lei Geral da Copa, inclusive, segundo Roman Borges (2012), com a teratológica tipificação de crimes para vedar os trabalhadores informais ao redor dos estádios.

A absurda garantia $n^{\circ} 10$ garante indenização à FIFA, seus representantes, empregados e consultores, bem como "colocá-los a salvo de todos os custos com processos, reivindicações e custos 
afins (inclusive honorários advocatícios), que possam ser incorridos ou sofridos ou ameaçados por outros". A garantia foi cumprida sem alterações ou adendos pelos arts. 22 a 24 da Lei Geral da Copa.

Outras garantias foram prometidas, mas a proposta do presente item já foi demonstrada. Seu objetivo é suscitar a questão: como o Poder Executivo se sente competente para garantir medidas tão variadas, que se espalham nos âmbitos federal, estadual e municipal, e afirmar abertamente que tais garantias permanecerão vinculantes, válidas e executáveis contra o Brasil e seu governo, assim como a todos os estados e autoridades locais, até 31 de dezembro de 2014, independentemente de qualquer mudança no governo brasileiro ou de seus representantes, ou qualquer mudança nas leis e regulamentos do Brasil?

Seria suficiente responder a essa pergunta com referência à Constituição da República Federativa do Brasil de 1988, que confere ao Presidente da República função legislativa? O art. 60, II, concede a ele a possibilidade de propor emenda à Constituição; o art. 61 , § 1, trata dos casos de leis complementares e ordinárias de iniciativa privativa do Presidente da República; o art. 62 prevê as medidas provisórias; o art. 68 trata das leis delegadas. As hipóteses são inúmeras, como também são vários os estudos que tratam do tema (CASTRO, 1986; FERREIRA FILHO, 2007; CLĖVE, 2010; CLÈVE, 2011), mas ainda assim não parece ser possível justificar, a partir da mera descrição do texto constitucional, que o Executivo tem condições de garantir a edição de leis, já que esse papel, em teoria, é do Legislativo.

O início dessa resposta exige justamente uma revisão da teoria da separação dos poderes, o que se faz a seguir.

\section{Separação de poderes? A estrutura e os mecanismos do Estado contemporâneo na visão de Karl Loewenstein}

A obra de Karl Loewenstein, publicada originalmente m 1957 e depois em 1965, com um pós-escrito, trata essencialmente do poder 
político. Para o autor, o poder pode ser tratado a partir de um sentido neutro, funcional e não avaliativo, que denota apenas uma situação fática ou uma relação.

Para o nosso contexto as seguintes observações devem ser suficientes, e neste contexto deve-se notar que o poder é usado como um termo estritamente neutro, funcional e não-avaliativo, denotando nada mais que uma situação ou uma relação de fato que não é eticamente boa nem ruim. (LOEWENSTEIN, 1965, p. 6). ${ }^{3}$

Nesse sentido, a sociedade é um sistema de relações de poder dentro do qual o poder político se sobressai, uma vez que é o mais adequado para regular as relações. O controle da sociedade, aqui, resume-se à função de criar a política ou de decidir sobre ela, bem como na habilidade dos detentores do poder de garantir a obediência das regras por seus destinatários. Segundo Loewenstein (1965, p. 6-7), "o controle social, no sentido mais estrito da ciência política contemporânea, é a função de criar ou decidir sobre a política e a capacidade dos detentores de poder para fazer os destinatários obedecerem à decisão política". ${ }^{4}$

A observação do poder político é essencial para examinar o processo governamental. Em primeiro lugar, a relação entre os detentores de poder tem como resultado a classificação dos diversos sistemas políticos. Além disso, há que se observar três diferentes estágios do processo político: i) o momento de atribuição de poder, ou seja, a forma como o poder político é obtido; ii) o momento de exercício do poder; e iii) como o exercício de poder é controlado (LOEWENSTEIN,1965, p. 9). Diga-se desde já que Loewenstein dedicou a maior parte de seus

3 Tradução livre de: "For our context the following observations must suffice, and in this context it should be noted that power is used as a strictly neutral, functional, and non-evaluative term, denoting nothing but a factual situation or relationship which is ethically neither good nor evil." (LOEWENSTEIN, 1965, p. 6).

4 Tradução livre de: "Social control, in the narrower sense of contemporary political science, is the policy-making or policy-deciding function and the ability of the power holders to make the power adressees obey the policy decision." O controle social, no sentido mais estrito da ciência política contemporânea, é a função de criar ou decidir sobre a política e a capacidade dos detentores de poder para fazer os destinatários obedecerem à decisão política (LOEWENSTEIN, 1965, p. 6-7). 
estudos ao último desses itens, mas nem por isso deixou de apresentar uma visão mais do que própria para o Estado contemporâneo.

A visão do autor a respeito do sistema político gira em torno das relações estabelecidas entre os diversos detentores de poder e seus destinatários. Todo Estado em que essas relações sejam entre instituições governamentais pode ser considerado um sistema político. Para diferenciá-los, o autor propõe dois conceitos-chave: as ideologias e as instituições. Instituições são o aparato pelo qual o processo de poder funciona em uma sociedade organizada, já a ideologia são os valores subjacentes às instituições, suas finalidades ou telos. A imbricação da ideologia com as instituições justifica, para o autor, a perda de funcionalidade de instituições quando estas são mecanicamente transplantadas para outro Estado, pois a ideologia trata de transformálas. O sistema eleitoral, por exemplo, perde seu sentido quando aplicado em uma sociedade com ideologia totalitária (LOEWENSTEIN, 1965, p. 9-11).

Tudo isso é apresentado para que se possa apresentar a definição de sistema político de Loewenstein: "é uma sociedade estatal imbuída de uma ideologia concreta - política, socioeconômica, ética ou moralreligiosa - à qual corresponde, a seu turno, instituições especificamente criadas para a realização da ideologia dominante" (LOEWENSTEIN, 1965, p. 11). ${ }^{5}$ A partir dessa definição, apresentam-se dois sistemas políticos: o autocrático, no qual o processo político está concentrado em uma única pessoa ou grupo; e o constitucionalismo democrático, no qual se inserem todas as formas de governo, com a atuação de diversos detentores de poder, como o presidencialismo e o parlamentarismo. 0 critério, como se vê, é bastante simples: o poder pode ser concentrado ou compartilhado.

Para a finalidade aqui proposta, serão levados em consideração apenas os apontamentos destinados ao processo de poder compartilhado,

\footnotetext{
5 Tradução livre de: "It is a state society imbued by a concrete ideology - political, socioeconomic, ethical or moral-religious - to which correspond, in turn, specific institutions intended for the realization of the dominant ideology." (LOEWENSTEIN, 1965, p. 11).
} 
ao qual se pode denominar de constitucionalismo democrático. Nesse ponto, o autor ora em análise pergunta quem são os detentores de poder. Essa resposta só pode ser apresentada a partir de um estudo do Direito Constitucional em conjunto com a Ciência Política, segundo Loewenstein (1965, p. 14), pois a realidade do processo político só pode ser verificada a partir de uma distinção pragmática entre os detentores formais de poder, pela investidura constitucional, com os detentores invisíveis que influenciam e determinam o processo indiretamente.

Dentre os detentores formais de poder, identificam-se: i) o governo, a quem se atribuem as funções de decisão e execução da política; ii) a assembleia, como órgão representante dos destinatários do poder (povo), costumeiramente dotado do poder legislativo e de funções de controle; a assembleia se tornou uma genuína representação do povo quando, com a extensão do sufrágio, sua composição passou a corresponder às diversas correntes políticas do eleitorado, organizadas por meio de iii) partidos políticos. Por fim, iv) as cortes também são identificadas como detentoras de poder quando a elas se atribui a competência para o controle de constitucionalidade (LOEWENSTEIN, 1965, p. 1415). Mais recentemente, a literatura descreve como competência das cortes proferir as chamadas sentenças estruturantes (FISS, 1978; LORENZETTI, 2010; ARENHART, 2013; MARINONI, 2013).

Já a descoberta dos detentores invisíveis de poder não pode ser realizada sem um aprofundamento sociológico. Localizá-los exige profundo conhecimento do sistema e de seus meandros, mas o autor aponta para grupos organizados de forma distinta dos partidos políticos e para os conglomerados de telecomunicação como os exemplos mais comuns dessa categoria de atores (LOEWENSTEIN, 1965, p. 16).

Tem-se, assim, delineados os conceitos básicos e a definição dos principais participantes do constitucionalismo democrático. Com isso, é possível passar às últimas contribuições de Loewenstein pertinentes para o problema em análise: a anatomia do processo governamental.

O autor expõe de modo bastante breve os modelos anteriores de classificação e organização dos governos. Apresenta as visões 
da Política de Aristóteles (2008), do Príncipe de Maquiavel (2007), do Espírito das Leis de Montesquieu (2005) e da Ascenção e Declínio de Roma de Guglielmo Ferrero (2012) apenas para concluir que nenhuma delas é satisfatória, pois não correspondem à realidade do processo de poder atual. Segundo Loewenstein (1965, p. 29), uma classificação eficaz deve ser obtida pelo exame comparado das estruturas governamentais e corresponde às figuras já mencionadas do constitucionalismo e da autocracia. O ponto que demarca as diferenças entre os dois é a forma de distribuição do poder: enquanto na autocracia o poder está concentrado nas mãos de um sujeito ou de um grupo, o constitucionalismo é marcado pela simples característica de um poder compartilhado.

Esse compartilhamento de poder teve sua primeira construção teórica com a "separação de poderes", que visava garantir as liberdades individuais e regular o poder dos governantes. Aorigem da construção tem em John Locke (1980) e no já citado Montesquieu o seu desenvolvimento, e assim permaneceu até os dias de hoje: somente com detentores de poder independentes um do outro e capazes de estabelecer freios e contrapesos é que se pode proteger o povo do abuso do poder. "Desde então, a separação de poderes tem sido o equipamento padrão do estado constitucional" 6 , ainda que os Estados contemporâneos tenham um funcionamento completamente diferente. Veja-se como exemplo o parlamentarismo inglês, no qual o Poder Executivo se confunde com o Poder Legislativo, tanto nas pessoas que o exercem como nas funções que ocupam: os membros do governo são membros do Parlamento e o governo é integrado a este (LOEWENSTEIN, 1965, p. 35).

O que a teoria da separação dos poderes ainda pode ensinar é que o Estado deve realizar várias atividades, e que elas são melhor empreendidas se houver uma divisão entre os órgãos destinados a cumpri-las. Nesse sentido, Loewenstein propõe que o tratamento dessas diferentes atividades seja denominado pelo termo "função", pois preserva o conceito de Estado como a concentração do poder político.

6 Tradução livre de: "Ever since, the separation of powers has been the standard equipment of the constitutional state." (LOEWENSTEIN, 1965, p. 35). 
A separação dos poderes é meramente o método clássico para formular a necessidade para o exercício partilhado e mutuamente controlado de poder político. O que é coloquialmente, ainda que incorretamente, chamado de separação de poderes é, operacionalmente, apenas a distribuição das funções estatais específicas entre os diferentes órgãos do Estado. O termo 'poderes', firmemente estabelecido como tal, deve, neste contexto, ser entendido como meramente figurativo. Na discussão a seguir, por isso, 'separação de funções' é usado de preferência a 'separação de poderes'. (LOEWENSTEIN, 1965, p. 36). ${ }^{7}$

Essa revisão também facilita a tarefa de abandonar a separação clássica do Executivo, Legislativo e Judiciário e buscar um novo tripartismo a partir da análise do processo de poder político. ${ }^{8}$ Assim, a nova tríade proposta gira em torno da política e se divide em três novas funções: determinação, execução e controle.

A função de determinação política refere-se às decisões fundamentais do Estado. Dizem respeito a questões políticas, socioeconômicas ou até mesmo morais (LOEWENSTEIN, 1965, p. 43). Independentemente da forma de governo, é seguro afirmar que a função de determinação é exercida em conjunto pelo governo e pelo parlamento, ao menos nos Estados que seguem o sistema de constitucionalismo democrático.

A segunda função é a de execução política. Trata-se do ofício de implementar as decisões tomadas pelos representantes da primeira função (LOEWENSTEIN, 1965, p. 46-48). No Brasil, costuma-se denominar essa função como a de administração, mas sua extensão é

7 Tradução livre de: "The separation of powers is merely the classical way of formulating the need for the shared and mutually controlled exercise of political power. What is colloquially, if erroneously, spoken of as the separation of powers is operationally only the distribution of specific state functions among different state organs. The term 'powers', firmly established as it is, must, in this context, be understood to be merely figurative. In the following discussion, therefore, 'separation of functions' is used in preference to 'separation of powers'." ( LOEWENSTEIN, 1965, p. 36).

8 Outras propostas de revisão da separação dos poderes podem ser encontradas, como a de Ackerman (1999-2000, p. 633). 
ainda maior. A execução das decisões é realizada pelos três poderes, como estabelecido pela Constituição de 1988: o Executivo é responsável direto pela implementação das decisões; o Legislativo edita normas que permitem o Estado agir; enquanto o Judiciário tem, na doutrina clássica sobre a jurisdição, a função explícita de executar as políticas de forma individualizada - ou atuar na vontade da lei (CARNELUTTI, s.d.; CHIOVENDA, 1969).

O controle da política é a função que encerra a nova divisão proposta por Loewenstein (1965, p. 48-52). Trata-se da função que se confunde com o próprio constitucionalismo, pois a sua história é a busca pelos mecanismos mais eficientes para limitar o poder político (SOUZA NETO; SARMENTO, 2013). No Brasil, o controle do poder é a função que mais tem preocupado a doutrina jurídica, especialmente no que diz respeito ao controle de constitucionalidade exercido pelas cortes. Por esse motivo, inclusive, as considerações de Loewenstein e dos demais autores que tratam do tema não serão abordadas.

Tem-se, assim, uma nova forma de se conceber a estrutura do Estado, a partir da proposta tripartida de determinação, execução e controle do poder político. Com esses critérios, é possível classificar os modelos de governo dentro das democracias constitucionais. Loewenstein identifica ao menos cinco: democracia direta, "governo assemblear", parlamentarismo, presidencialismo e o chamado governo diretório, específico do sistema suíço (LOEWENSTEIN, 1965, p. 72-74).

A exposição dos cinco não contribuiria para o presente estudo. Por esse motivo, limita-se a exposição apenas ao parlamentarismo e ao presidencialismo. A respeito do primeiro, deve-se observar apenas que ele se configura na medida em que se procura um equilíbrio dos dois detentores de poder por meio da integração entre ambos: o governo e o parlamento. Esse equilíbrio pode pender para o parlamento (como no caso francês) ou para o gabinete (Reino Unido).

Já no presidencialismo, governo e parlamento são expressamente separados, mas obrigados a cooperado. Em vez da integração entre ambos, o presidencialismo exige a coordenação dos detentores de poder 
para exercer o poder de determinação de políticas. A marca distintiva dessa forma de governo, portanto, é a "interdependência por coordenação", cujo significado é de que "detentores de poder independentes atuam de forma autônoma dentro de suas respectivas esferas de competência, mas, em pontos pré-estabelecidos de contato, eles são forçados a cooperar" (LOEWENSTEIN, 1965, p. 107). ${ }^{9}$

Para haver cooperação, um requisito parece essencial: o Presidente, como líder de seu partido, deve influenciar a atitude de seus pares no congresso (LOEWENSTEIN, 1965, p. 108).

A constatação de Loewenstein revela que o Presidente, sozinho, não é capaz de governar. Essa é uma das principais provas de que sua proposta de divisão tripartida é mais útil do que a separação clássica de poderes, pois o Presidente não possui a função de determinação de políticas por si só. Segundo o autor, "O partido político tornou-se o elo perdido entre os detentores do poder constitucionalmente isolados. É o óleo de lubrificação de toda a máquina do Estado, sem o qual esta teria se visto diante de impasses sem solução" (LOEWENSTEIN, 1965, p. 109). ${ }^{10}$ Para ser, de fato, o detentor do poder de decisão, ele deve ter uma base aliada com assentos no Legislativo. Essa observação conclui a exposição deste tópico: os detentores de poder no presidencialismo só conseguem determinar novas políticas por meio dos partidos políticos. São eles os catalisadores do complexo sistema presidencialista.

A conclusão do autor, portanto, é que a função de determinação de políticas no presidencialismo deve ser orquestrada pelo Presidente e respaldada pela base aliada com assentos no Legislativo. Um Presidente sem apoio não possui poder de decisão, o que resulta em um impasse político. Dessa forma, a fim de investigar se um Presidente

Tradução livre de: "Interdependence by co-ordination, on the other hand, means that the independent power holders function autonomously within their respective sphere of action but that, at pre-established points of contact, they have to co-operate." (LOEWENSTEIN, 1965, p. 107).

10 Tradução livre de: "The political party became the missing link between the several constitutionally isolated power holders. It is the lubricating oil of the entire state machinery without which the latter would have run into unbreakable deadlocks." (LOEWENSTEIN, 1965, p. 109). 
pode prometer a criação de uma legislação, é preciso examinar o funcionamento do presidencialismo de coalizão e seu grau de eficiência na determinação de políticas.

\section{Presidencialismo de coalizão}

O termo "presidencialismo de coalizão" foi cunhado por Sergio Abranches (1988), com a publicação de célebre trabalho. Fernando Limongi observa que o fato de o presidencialismo brasileiro exigir adjetivação indica que o sistema nacional tem algo de peculiar ou especial (LIMONGI, 2006), ou ao menos que essa característica deve ser investigada. Para Abranches (1988, p. 21-22), no período em que seu texto foi redigido, este elemento se destacava: o "Brasil é o único país que, além de combinar a proporcionalidade, o multipartidarismo e o 'presidencialismo imperial', organiza o Executivo com base em grandes coalizões". Nesse sentido, o presidencialismo de coalizão seria marcado pelo critério de formação da base parlamentar de apoio ao Presidente (LIMONGI, 2006, p. 19).

Ocorre que o ano de 1988 não foi comum para o Estado brasileiro. Pelo contrário, o período era de mudança e as análises datadas tinham a marca das incertezas ou da busca de um sistema democrático. É por essa razão que o trabalho de Abranches não pode ser utilizado como o paradigma do presidencialismo de coalizão, nem pode essa figura ser vista como uma característica particular do Estado brasileiro.

Pelo contrário, a coalizão é uma característica presente em grande parte dos governos democráticos constitucionais (CHEIBUB; PRZEWORSKI; SAIEGH, 2002). Como expõe Arend Lijphart (2012), seja no modelo de Westminster, seja no modelo Consensual ${ }^{11}$, o Executivo e o Legislativo têm uma relação bastante próxima, que pode se desenvolver

11 Segundo Lijphart (2012, pos. 197 de 5711), o modelo de Westminster, ou majoritário, pode ser representado pela noção de "maioria das pessoas", enquanto o modelo Consensual seria definido por "quanto mais pessoas melhor". 
de duas maneiras. Ou o Executivo é dominante, como no exemplo inglês, em que o gabinete é composto pelos líderes de uma maioria coesa na House of Commons, e com isso ela pode contar que ficará no poder e saber que suas propostas legislativas serão aprovadas; ou há um balanço de poder entre o Executivo e o Legislativo, como na Suíça, onde o poder é dividido em amplas coalizões, mas há independência de mandatos dos governantes e parlamentares (LIJPHART, 2012, pos. 348 e 660 de 5711). Segundo Lijphart (2012, pos. 579 de 5711), "esta separação formal de poderes tornou o executivo e o legislativo mais independentes e sua relação muito mais balenceada que as relações gabinete-parlamento [...] britânico [...], nos quais o gabinete é claramente dominante". ${ }^{12}$ Para obter qualquer alteração legislativa significativa, é certo, nos dois casos, que o representante do governo deve ter o apoio dos legisladores, sob pena de se chegar a um impasse.

Em que pese Lijphart excluir o Brasil de sua análise empírica, Fernando Limongi (2006) considera que o sistema político nacional funciona, do ponto de vista estrutural, nos mesmos moldes que outras democracias ditas avançadas ou consolidadas. A organização do processo decisório é marcada pela delegação do poder de agenda (LIMONGI; FIGUEIREDO, 2009) ao representante da função executiva, que, com o apoio de sua base no Legislativo, é capaz de alterar o status quo. ${ }^{13}$ Nesse sentido, George Tsebelis (2002, pos. 919 de 7562) vê o processo decisório como uma sequência de movimentos em que determinados atores políticos fazem propostas enquanto outros as aceitam ou as rejeitam. Esse primeiro movimento é o chamado poder de agenda, que dá a seu detentor uma grande vantagem: ele pode considerar a opinião dos demais atores e selecionar o melhor resultado possível (TSEBELIS, 2002, pos. 933 de 7562).

\footnotetext{
12 Tradução livre de:"This formal separation of powers has made both the executive and the legislature more independent, and their relationship is much more balanced than cabinetparliament relationships in the British, New Zealand, and Barbadian cases in which the cabinet is clearly dominant". (LIJPHART, 2012, pos. 579 de 5711).

13 Como visto na ótica de Tsebelis (2002). Nesse sentido, ver também Tomio e Robl Filho (2013).
} 
Para transportar o argumento de Tsebelis para o sistema político brasileiro, dois indicadores podem contribuir para a análise da operação dos governos: a taxa de sucesso das iniciativas do Executivo, "que nada mais é do que a proporção do que é aprovado sobre o total enviado por este poder"; e a taxa de dominância sobre a produção legal, que é "a simples divisão das leis cuja proposição se deve ao Executivo pelo total de leis aprovadas no período" (LIMONGI, 2006, p. 21). Nos regimes parlamentaristas, as taxas de sucesso e de dominância costumam se concentrar em torno dos 90\% (LOWENBERG; PATTERSON, 1979).

Isso quer dizer, portanto, que aproximadamente $90 \%$ das propostas legislativas apresentadas pelo representante do Executivo são aprovadas e, ao mesmo tempo, 90\% das leis produzidas por um Estado são propostas pelo Executivo. Essa simples informação a respeito do modelo parlamentarista já é suficiente para reforçar a importância da contribuição de Loewenstein (1965): o Executivo possui evidente (e empiricamente comprovada) função de determinação.

Para Limongi, a explicação das taxas de sucesso e de dominância está na disciplina partidária, típica dos governos parlamentaristas. Seu funcionamento ordinário repousa na supremacia do Executivo, com amparo do Legislativo. Essa tendência, porém, não parece ser uma exclusividade da forma de governo, mas sim das democracias constitucionais: "o Brasilé não é tão diferente dos países parlamentaristas" (LIMONGI, 2006, p. 23).

Com relação aos indicadores da operação do governo, o Executivo brasileiro obteve, de 1988 a 2006, sucesso de 70,7\% e dominância de 85,6\% (LIMONGI, 2006, p.23). ${ }^{14}$ Se comparados com o período anterior,

14 Segundo Limongi (2006, p. 23): "Cabe notar que a definição de sucesso adotada é exigente, pois pede que a matéria seja aprovada ao longo do mandato do presidente que submeteu a medida. As variações por presidentes são pequenas e independem da sua base de apoio. É certo que Fernando Collor, o único presidente do período a formar coalizões minoritárias, teve o pior desempenho nesse quesito entre todos os presidentes, aprovando $65 \%$ dos projetos que submeteu. Mas a variação é menor que a estabilidade. A taxa de sucesso para Itamar foi um ponto superior à de Collor e os demais presidentes ficaram um pouco acima dos $70 \%$. [...] Uma vez mais, não há variações significativas entre os mandatos. Collor e Sarney têm os valores mais baixos, em torno dos $77 \%$. Itamar e Lula estão acima dos $90 \%$, enquanto Fernando Henrique teve taxa similar em seus dois mandatos: $85 \%$." 
nos quais se tem dados disponíveis (1949-1964), há um evidente contraste: sucesso de $29,5 \%$ e dominância de 39\% (LESSA, 2001). A síntese de Limongi (2006, p. 24) é acurada: no período atual, "o que o Executivo submete ao Legislativo é, em geral, aprovado".

A explicação para esses altos índices de sucesso e dominância está justamente no apoio que os presidentes eleitos sob a égide da Constituição de 1988 têm nas casas legislativas (MENEGUELLO, 1997). Existe uma sólida coalizão partidária, demonstrada pelo índice de disciplina média ${ }^{15}$ de $87,4 \%$. Ou seja, a bancada do governo atua com parâmetros próximos da unanimidade quando se trata de aprovar ou negar um determinado ato. Em dados mais recentes, tem-se que o governo de Dilma Rousseff manteve os altos níveis de disciplina, aproximando-se de 90\% no ano de 2011 (APOIO..., 2012).

É interessante notar a progressiva mudança de posicionamento de Fernando Limongi (2006). Em 1998, o autor sustentava que o governo não tinha apoio pleno e incondicional, mas que o Congresso não era um obstáculo intransponível á implementação da agenda do Executivo (LIMONGI; FIGUEIREDO, 1998). Sua conclusão mais recente é ainda mais direta:

o que realmente importa não é a magnitude da disciplina, mas a previsibilidade, isto é, se líderes têm como prever os resultados, se podem garantir vitórias contando apenas com suas bancadas. E isso ocorre no Brasil. O plenário é extremamente previsível. (LIMONGI, 2006, p. 24).

Pelos dados apresentados, não é apenas o plenário brasileiro que é previsível. Mais do que isso, o que essas considerações demonstram é que existe no constitucionalismo democrático brasileiro uma evidente formação de um poder nos moldes descritos por Loewenstein: a coalizão formada entre o Presidente e sua base aliada no Congresso forma o que se chama "poder de determinação".

\footnotetext{
15 A disciplina média é definida como a "proporção de deputados filiados a partidos que receberam pastas ministeriais que votaram em acordo com a indicação expressa do líder do governo”. (LIMONGI, 2006, p. 24).
} 
Trata-se, em verdade, de um poder que dificilmente se veta no processo legislativo, o que se observa pela alta taxa de sucesso. É essa reunião de poderes que efetivamente decide sobre as políticas, fato comprovado pela sua taxa de dominância.

O que os dados empíricos revelam é que a clássica separação de poderes não persiste nas democracias constitucionais. Em um plano formal, ainda é possível identificar as três funções claramente, no entanto, a partir de uma análise racional e com critérios materiais, fundados na organização e no exercício do poder, o que se observa é uma coordenação orquestrada pelos partidos políticos e pelas coalizões. No âmbito legislativo, pelo menos, não há uma clara separação entre o Presidente e o Legislativo.

\section{Conclusão}

Feitas as considerações dos itens 2 e 3, parece possível apresentar uma resposta para a questão inicialmente formulada: 0 que explica a certeza do Presidente da República e de seus Ministros quanto à aprovação legislativa das garantias prometidas à FIFA? Ou, ainda, que elementos possuem os representantes do Poder Executivo para garantir (ou prometer) a edição legislativa? Por fim, como afirmado na Carta de Intenções do governo federal à FIFA, tem o Presidente e os Ministros de Estado competência para afirmar que aprovariam (ou pediriam ao Congresso, estados ou autoridades locais) todas as leis, portarias e outros regulamentos necessários para cumprir as promessas contidas naquele documento?

A partir da clássica teoria da separação dos poderes, a resposta para todas as perguntas acima seria um ríspido não. Apesar disso, a realidade política das democracias constitucionais exige uma análise mais cautelosa, como se buscou apresentar.

Assim, diante da teoria tripartida de funções apresentada por Karl Loewenstein e da comprovação empírica de que existe um presidencialismo de coalizão em pleno vigor no sistema brasileiro, outra resposta pode ser 
formulada, nos seguintes termos: sendo a coalizão formada em torno do Presidente da República o conjunto de representantes detentores da função de determinação, sendo o Presidente o principal detentor do poder de agenda dessa função e com as taxas de sucesso de suas propostas legislativas em níveis superiores a $70 \%$, é perfeitamente razoável que o Presidente apresente a quem quer se seja promessas ou garantias que envolvam a criação ou modificação da legislação.

Vistas nesses termos, as promessas do Brasil à FIFA não são, por si só, atos ilícitos ou supostamente inconstitucionais. Nas palavras de Bruce Ackerman (1999-2000, p. 729), honra-se "Montesquieu e Madison ao buscar novas formas constitucionais para superar esses desafios, mesmo à custa de transcender formulações trinitárias familiares". ${ }^{16} \mathrm{Com}$ isso, espera-se ter apresentado uma nova perspectiva de análise para o processo de decisão política e contribuído para o debate em torno da democracia.

\section{Referências}

ABRANCHES, Sérgio Henrique. O presidencialismo de coalizão: o dilema institucional brasileiro. Dados: Revista de Ciências Sociais, Rio de Janeiro, v. 31, n. 1, p. 5-33, 1988.

ACKERMAN, Bruce. The new Separation of Powers. Harvard Law Review, Cambridge, v. 113, n. 3, p. 633-729, 1999-2000.

APOIO de Dilma no Congresso é maior que de Lula. Exame, 19 jan. 2012. Disponível em: <http://exame.abril.com.br/brasil/politica/noticias/

16 Tradução livre de: "We honor Montesquieu and Madison best by seeking new constitutional forms to master these challenges, even at the cost of transcending familiar trinitarian formulations." (ACKERMAN, 1999-2000, p. 729). 
apoio-de-dilma-no-congresso-e-maior-que-de-lula>. Acesso em: 25 ago. 2013.

ARENHART, Sergio Cruz. A tutela coletiva de interesses individuais: para além da proteção dos interesses individuais homogêneos. São Paulo: Revista dos Tribunais, 2013.

ARISTÓTELES. A política. São Paulo: Edipro, 2008.

BARBOSA, Pedro Henrique et al. A soberania brasileira na organização de grandes eventos esportivos internacionais. Revista Brasileira de Direito Desportivo, São Paulo, n. 20, ano 10, p. 169-208, jul./dez. 2011.

BARON DE MONTESQUIEU, Charles-Louis de Secondat. O espírito das leis. São Paulo: Martins Fontes, 2005.

BRASIL. The Brazilian Football Confederation's Bid to Host the 2014 FIFA World Cup. Brasília, 2007.

BRASIL. Congresso Nacional. Lei $n^{\circ}$ 12.663, de 5 de junho de 2012. Dispõe sobre as medidas relativas à Copa das Confederações FIFA 2013, à Copa do Mundo FIFA 2014 e à Jornada Mundial da Juventude - 2013, que serão realizadas no Brasil; altera as Leis n. ${ }^{\circ} 6.815$, de 19 de agosto de 1980, e 10.671, de 15 de maio de 2003; e estabelece concessão de prêmio e de auxílio especial mensal aos jogadores das seleções campeãs do mundo em 1958, 1962 e 1970. Disponível em: <http://www.planalto.gov.br/ccivil_03/_ato2011-2014/2012/Lei/L12663. htm>. Acesso em: 25 ago. 2013.

CARNELUTTI, Francesco. Diritto e processo. Napoli: Morano, [s.d.].

CASTRO, Carlos Roberto de Siqueira. O congresso e as delegações legislativas. Rio de Janeiro: Forense, 1986.

CHEIBUB, José Antonio; PRZEWORSKI, Adam; SAIEGH, Sebastian. Governos de coalizão nas democracias presidencialistas e parlamentaristas. Dados: Revista de Ciências Sociais, Rio de Janeiro, v. 45, n. 2, p. 187-218, 2002.

CHIOVENDA, Giuseppe. Instituições de direito processual civil. São Paulo: Saraiva, 1969. v. 2. 
CLĖVE, Clèmerson Merlin. Medidas provisórias. 3. ed. São Paulo: Revista dos Tribunais, 2010.

Atividade legislativa do poder executivo. 3. ed. São Paulo: Revista dos Tribunais, 2011.

FERREIRA FILHO, Manoel Gonçalves. Do processo legislativo. 6. ed. São Paulo: Saraiva, 2007.

FERRERO, Guglielmo. The greatness and decline of Rome. Toronto: University of Toronto Libraries, 2012.

FISS, Owen. The civil rights injunction. Indianapolis: Indiana University Press, 1978.

INDONESIA'S bid to host the 2022 World Cup bid ends. Disponível em: <http://news.bbc.co.uk/sport2/hi/football/8577452.stm>. Acesso em: 25 ago. 2013.

LESSA, Renato. Aventuras do Barão de Munchausen: notas sobre a tradição presidencialista brasileira. In: LANZARO, Jorge (Org.). Tipos de presidencialismo y coaliciones politicas en America Latina. Buenos Aires: CLACSO, Consejo Latinoamericano de Ciencias Sociales, 2001. p. 137-162.

LIJPHART, Arend. Patterns of democracy. 2. ed. New Haven: Yale University Press, 2012. Edição Kindle.

LIMONGI, Fernando. A democracia no Brasil. Novos Estudos, São Paulo, n. 76, p. 17-41, nov. 2006.

LIMONGI, Fernando; FIGUEIREDO, Argelina. Bases institucionais do presidencialismo de coalizão. Lua nova, São Paulo, n. 44, p. 81-106, 1998.

LIMONGI, Fernando; FIGUEIREDO, Argelina. Poder de agenda e políticas substantivas. In: INACIO, Magna; RENNO, Lucio (Org.). Legislativo brasileiro em perspectiva comparada. Belo Horizonte: UFMG, 2009. p. 77-104. 
LOCKE, John. Second treatise of government. Indianapolis and Cambridge: McPherson, Hackett Publishing Company, 1980. Edição Kindle.

LOEWENSTEIN, Karl. Political power and the governmental process. 2. ed. Chicago: University of Chicago Press, 1965.

LORENZETTI, Ricardo Luis. Justicia colectiva. Buenos Aires: RubinzalCulzoni, 2010.

LOWENBERG, Gerhard; PATTERSON, Samuel. Comparing legislatures. Boston: Little Brown, 1979.

MAQUIAVEL, Nicolau. O príncipe. São Paulo: Hedra, 2007.

MARINONI, Luiz Guilherme. Teoria geral do processo. 7. ed. São Paulo: Revista dos Tribunais, 2013.

MENEGUELLO, Rachel. Partidos e governos no Brasil Contemporâneo (1985-1997). São Paulo: Paz e Terra, 1997.

ROMAN BORGES, Clara Maria. A criminalização do trabalhador informal brasileiro na Copa 2014. Revista Eletrônica Tribunal Regional do Trabalho do Paraná, Curitiba, v. 1, n. 11, p. 96-105, set. 2012. Disponível em: <http://www.mflip.com.br/pub/escolajudicial/index.jsp?ipg=67294> Acesso em: 25 ago. 2013.

SOUZA NETO, Claudio Pereira de; SARMENTO, Daniel. Direito constitucional: teoria, história e métodos de trabalho. Belo Horizonte: Fórum, 2013.

TOMIO, Fabrício Ricardo de Limas; ROBL FILHO, Ilton N. Empirical legal research: teoria e metodologia para a abordagem do processo decisório de controle de constitucionalidade no STF. In: VESTANA, Carolina Alves; SIQUEIRA, Gustavo Silveira (Org.). Direito e experiências jurídicas: debates práticos. Belo Horizonte-MG: Arraes Editores, 2013. v. 2. p. 96117.

TSEBELIS, George. Jogos ocultos: escolha racional no campo da política comparada. Tradução de Luiz Paulo Rouanet. São Paulo: Universidade de São Paulo, 1998. 
Veto players: how political institutions work. Princeton: Princeton University Press, 2002. Edição Kindle.

Recebido em: 10/02/2014 Aprovado em: 28/10/2014 